\title{
Experimental and Analytical Study on the KT-joints of the All-welded Steel Truss Bridge
}

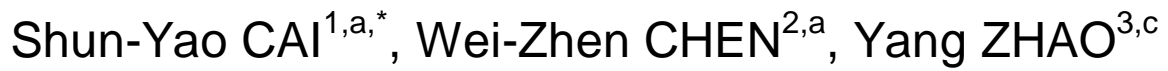 \\ 1,2Department of Bridge Engineering,Tongji University, 1239 SiPing RD, Shanghai, China \\ ${ }^{3}$ School of Civil Engineering and Communication, North China University of Water Resources and \\ Electric Power, Zhengzhou 450011, China \\ a'shunyaocai881025@126.com, btongji_bridge611@126.com, 'czyqingquan@qq.com \\ ${ }^{*}$ Corresponding author
}

Keywords: KT-joint, All-welded Steel Truss, Full-scale Fatigue Test, Structural Stress Method.

\begin{abstract}
In order to fully understand the anti-fatigue performance of KT-joints in the all-welded steel truss of Haihe Grand Bridge in Tianjing, two experiment--one fatigue test using a full-scaled KT-joint and the other fatigue test using two groups of T-components (a total of 8 components) cut out from the joints--and the finite element analysis were carried out. As revealed in the test result, the critical welds of the joint, under the design load or 5 million cycles of load, does not display fatigue failure; for the T-type components, after both Group A and Group B are subjected to 5 million cycles and 6 million cycles of load, respectively, only one component in Group A displays fatigue failure. The experiments are then well simulated by the finite element analysis. As verified by the experiments and the FE analysis, the KT-joints of the real bridges have adequate fatigue resistance, provided that the welding quality is rigorously controlled.
\end{abstract}

\section{Introduction}

Many research achievements have already been made concerning fatigue performance of circular and square KT-joint, but the researched KT-joint is usually used for thin-wall structure while the leader and branch pipes of the joint can be circular or square in shape[1,2]. The KT-joint, as discussed in this paper, with main member in box-type and branch member in H-type, is more commonly used for all-welded steel truss bridge. So far none of fatigue standards in any countries have classified joint fatigue for this type and few research achievements have been made on fatigue of this type of joint. Nevertheless, problems such as selecting right weld for this joint, stress distribution at weld joint and calculation of fatigue life must be solved before this type of all-welded joints can be widely applied. This paper makes experiments (such as fatigue tests on chord roof butt weld, web plate butt weld, and diagonal web flange butt weld, respectively) of full-scaled KT-joints, providing a reliable basis for fatigue design of this type of joint.

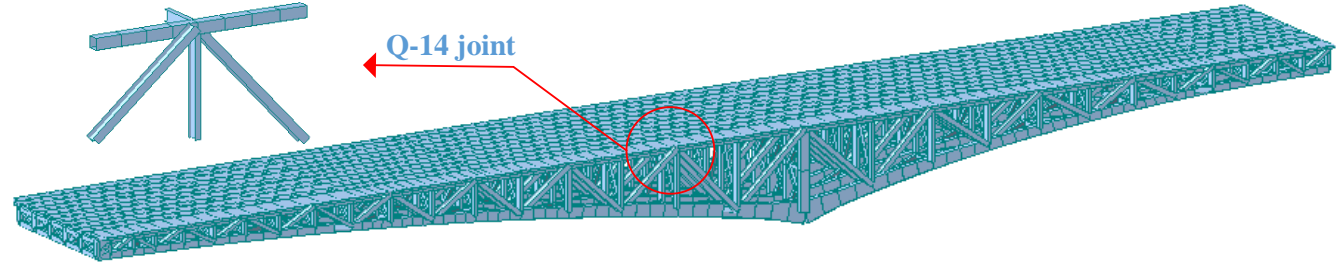

Fig. 1 Q14 Joint in the Bridge Elevation

Haihe Grand Bridge is one of the the two bridges on the west outer-ring highway in Tianjin Binhai New District. The bridge, an all-welded steel truss beam combination structure, has the main span arrangement of $95 m+140 m+95 m$, with all its chords and webs either vertically or horizontally welded via gusset plates. This paper is to study the upper chord of Q14 joint on the plane of longitudinal truss. When subjected to the most adverse load prescribed by the relevant design institute, the diagonal abdominal rod of Q14 joint has its tensile stress in the most unfavorable condition. As shown in Figure 1, Q14 joint is a KT-joint, with its diagonal web flange transversely butt welded with gusset plates. As a main bearing components, the 
joint most easily displays fatigue cracks under cycles of tensile stress. But the failure of this joint will lead to the failure of the whole bridge structure. As seen in Figure 2, the upper-chord is large. To ensure the joint strength and stiffness, stiffened diaphragms are used inside the chord at the weld face between the diagonal and vertical abdominal webs and the bottom plate of box chord. Obviously, the details of the joint is complicated, making fabrication, construction, and welding difficult. In addition, the stress in the joint is also complicated, needing careful study so as to prevent fatigue cracks in the component under cycles of tensile stress.

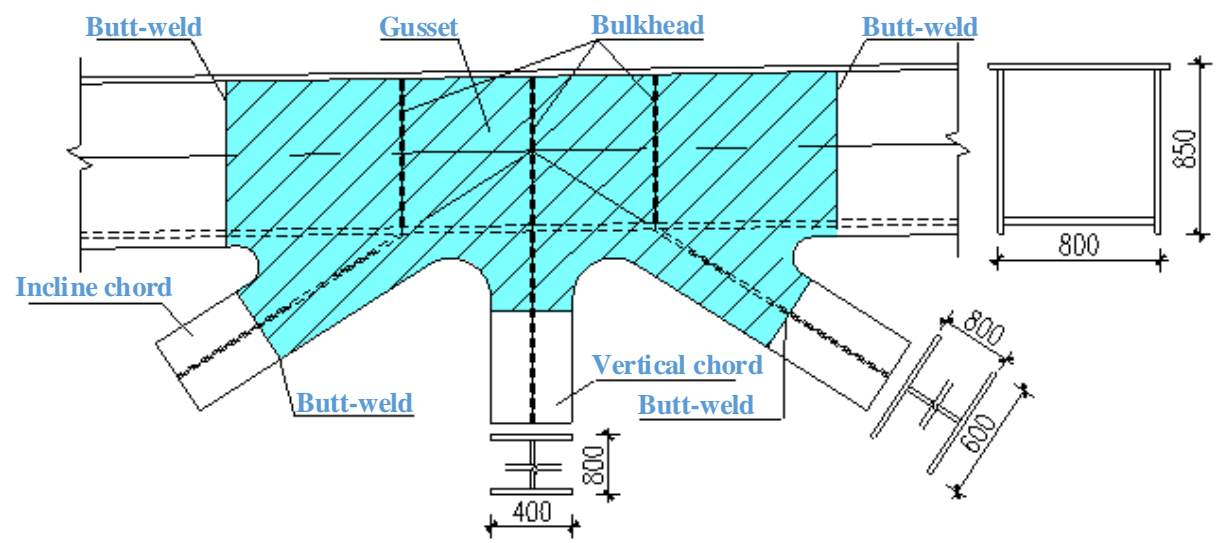

Fig. 2 The Geometry Shape and Sectional Drawing for KT-joint

\section{Specimens and Testing Method}

\section{Fatigue Test of KT-joint}

In order to truthfully reflect fatigue stress performance of the joint in the real truss bridge structure, the specimens for the experiment are made in a full scale of $1: 1$, with their structure completely the same as that of the real joints. However, considering the conditions such as the load capacity of the laboratory, the floor space, and test equipment, as well as the concern of Q-14 joint with respect to the fatigue performance of the butt weld between the tensile diagonal web flange plate and the gusset plate, members such as the vertical rod, the diagonal web member on the other side, and the chord length are all deleted, as shown in Figure 2 about the test joints and their sectional dimensions.

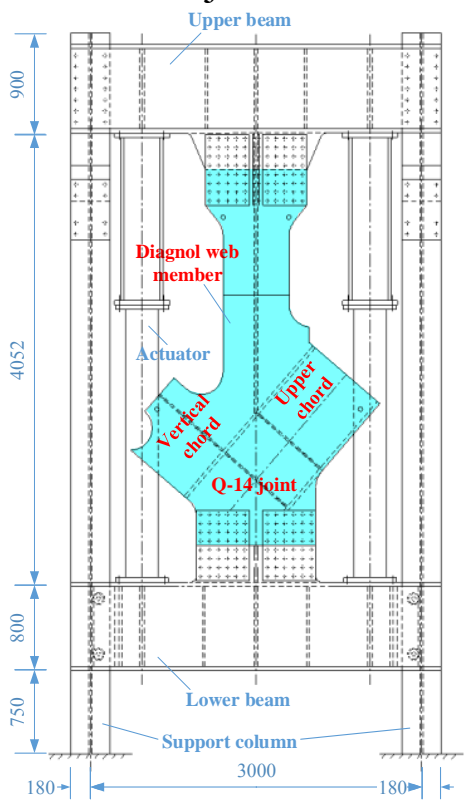

a) Load diagram of full-scaled KT specimen

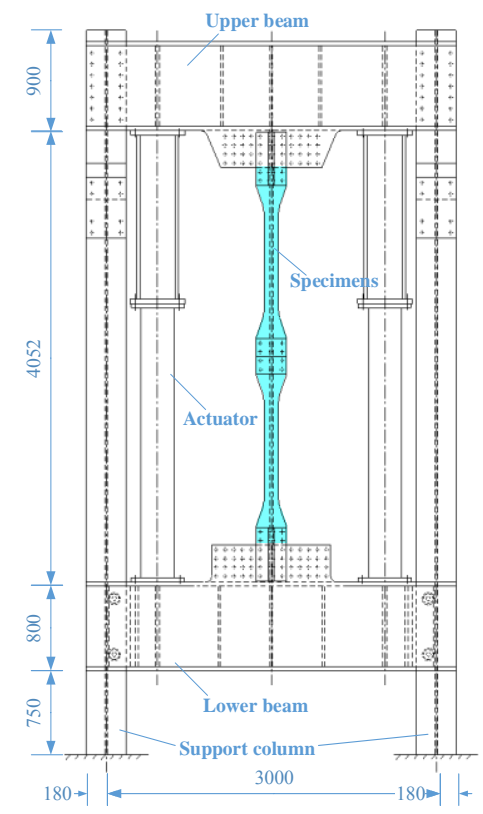

b) Load diagram of T-weld joint specimens

Fig. 3 Load Installation Diagram of Fatigue Test 
As seen in Figure 3, the fatigue load is applied in form of two tensions. The tensions are first passed onto the lower cross beam, and then via the cross beam onto the joint to add to the tension in the diagonal web, with the concurrent force passing through the heart of diagonal abdominal rod. Under the most adverse joint load (axial force and bending moment) as prescribed by the relevant design institute, the nominal load stress amplitude of diagonal abdominal web of specimen joint $\Delta \sigma_{n}$ is made the same as the stress amplitude of the actual joint $\Delta \sigma_{\text {actual }}$. Given testing conditions, the actual fatigue load is simultaneously applied by two fatigue testers with the maximum output load of $500 \mathrm{kN}$. In the experiment, the output fatigue load is ranged within $200 \sim 970 \mathrm{kN}$, corresponding to $16.44 \mathrm{MPa}$, the nominal stress amplitude of the diagonal web.

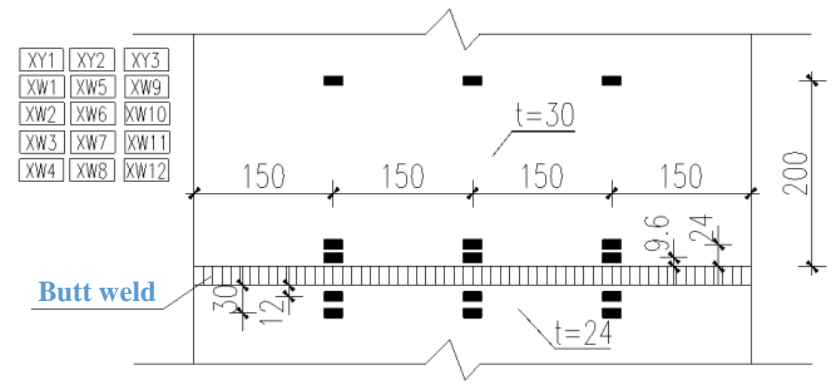

Fig. 4 Arrangement of Strain Measuring Points for Butt Weld between Diagonal Web Flange and Gusset Plate

As shown in Figure 4, several unidirectional strain gages are arranged on both sides and also one side of the weld as well as at the places far away from the weld in order to investigate the structural stress at various welds and weld toes of the tested joints.

\section{Fatigue Tests of Chord Roof Butt Weld, Web Plate Butt Weld, and Diagonal Web Flange Butt Weld}

The main pipe of KT-joint is in a box section and the branch pipe in a $\mathrm{H}$ section. The types of weld include butt weld and fillet weld. The butt weld under vertical tension is selected in the analysis as the object of fatigue test.

The fatigue designed for the test distinguishes three types: (1) chord roof butt weid; (2) chord web butt weld; (3) diagonal web flange. After optimization of the design, the welded joint specimens of the first two types adopt the same $\mathrm{H}$ section while that of the third type adopts $\mathrm{T}$ section. To ensure that the residual stress of the weld in specimens is the same as that in the actual structure, all the specimens for the test are cut and fabricated in full-scale from box chord and $\mathrm{H}$ diagonal web member, as shown in Figures 5 and 6.

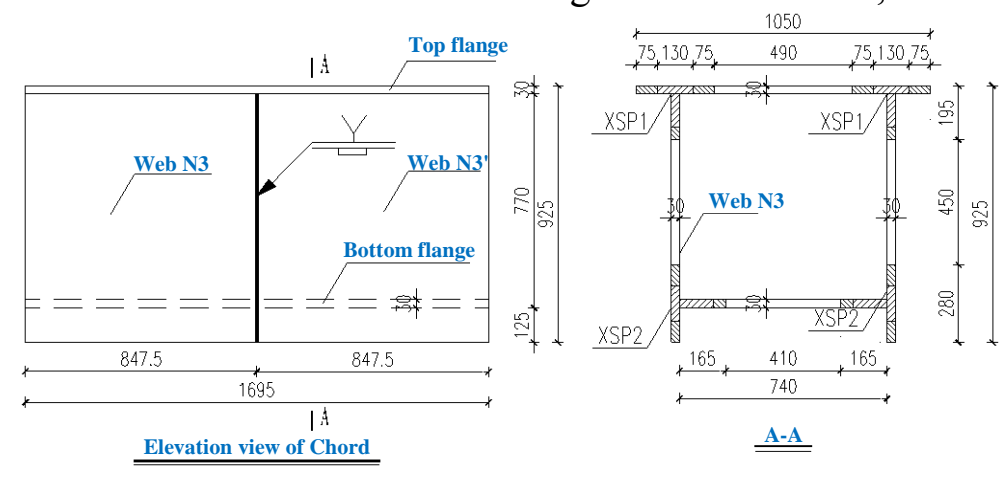

Fig. 5 Box Chord Web Butt Weld

As shown in Figure 3, the fatigue loading mode and test equipment are the same as that for the fatigue test of full-scaled KT-joints. To enhance test efficiency, every four specimens are arranged into groups to be connected in series and every two connected series are further connected in parallel so that each fatigue test can be applied to four specimens at one time. The specimen grouping is tabulated in Table 1. The specimens are then subjected to the load in the following sequence: Group A is put under fatigue load till one of the specimen is damaged due to fatigue failure; the load machine is stopped, the damaged specimen is replaced with Specimen FSP3 from Group B, and the load test continues; after all the specimens from 
Group A is replaced with the specimens from Group B, the load test continues till the FSP3 is damaged. Then, the alternate specimen is used for the replacement and the load test continues. The output fatigue load for the test is ranged within $200 \sim 970 \mathrm{kN}$. The corresponding theoretical nominal stress for Group A specimens (XSP1、XSP2) is 51.33MPa. The corresponding theoretical nominal amplitude for Group B specimens (FSP3) is 53.12MPa.

As shown in Figure 7, several unidirectional strain gages are arranged on both sides and one side of the weld, at the places far away from the weld, and at top of scallop hole in order to investigate the structural stress, the hot spot stress concentration factor and the scallop hole stress concentration factor at various transverse butt welded toes.

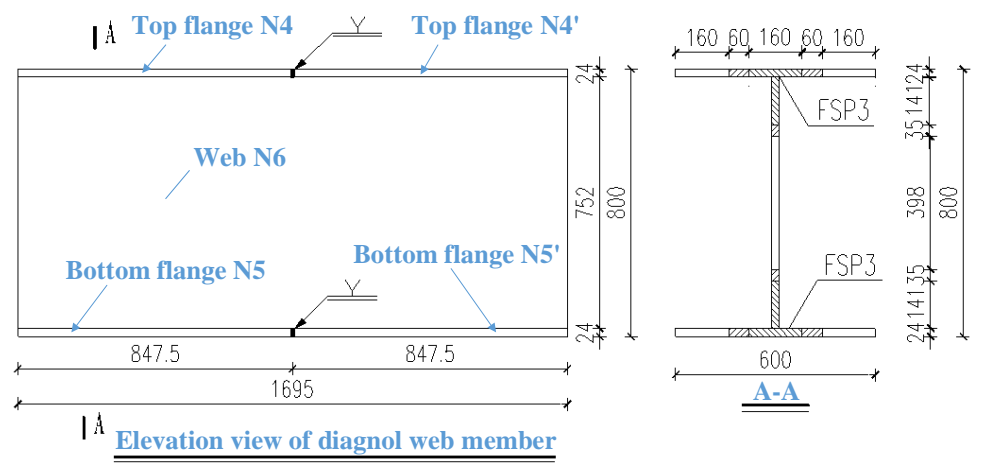

Fig. 6 H Diagonal Web Member Flange Butt Weld

Tab. 1 Specimen Groups

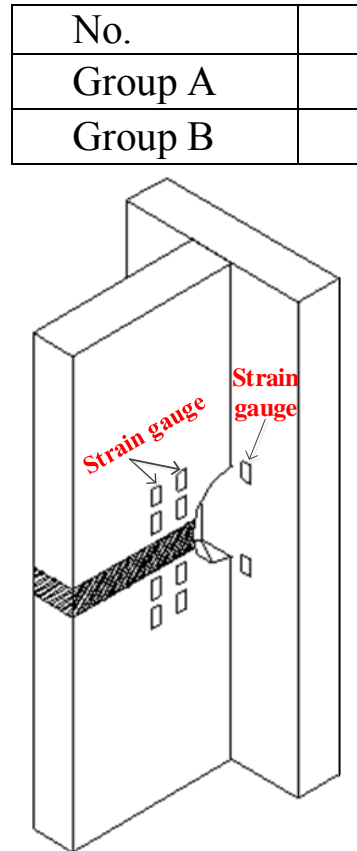

a)XSP1 specimen

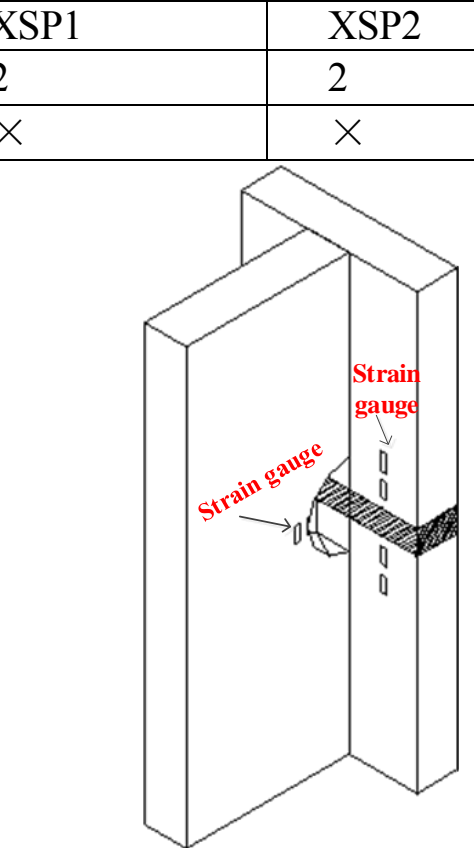

b)XSP2 specimen

\begin{tabular}{|l|l|}
\hline FSP3 \\
\hline & $\times$ \\
\hline
\end{tabular}

Fig. 7 Arrangement of Strain Measuring Points for Fatigue Test of T Specimens

\section{Fatigue Test Result and Analysis}

\section{Fatigure Test of KT Joint}

After application of 2 million cycles of load, the diagonal web flange is founded, via magnetic particle testing, to have surface cracks at diagonal web flange butt weld near the edge of the web, as shown in Figure 8. After application of 3.5 million cycles of load and 5 million cycles of load, the second test via 
magnetic particle method does not find obvious development of the cracks. It is then concluded that the cracks may be the initial surface crack caused by residual stress rather than the fatigue cracks by the fatigue load. After the application of 5 million cycles of load when the fatigue test stops, the magnetic particle testing finds no cracks in either the butt weld between the diagonal abdominal web and $\mathrm{Y}$-joint at the bottom plate of box chord or the butt weld between clapboard and T-joint weld at bottom plate of box chord, all the specimens displaying no fatigue failure.

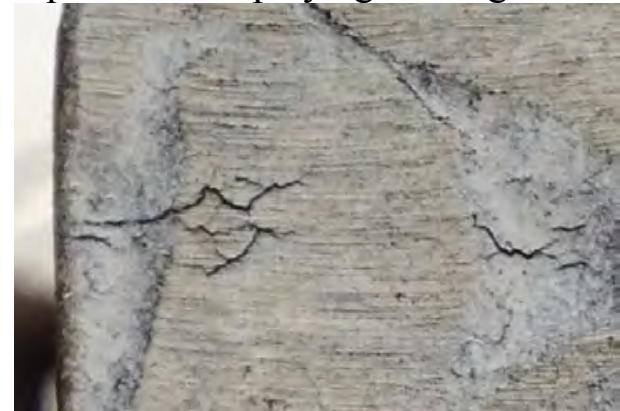

a) 2 million cycles

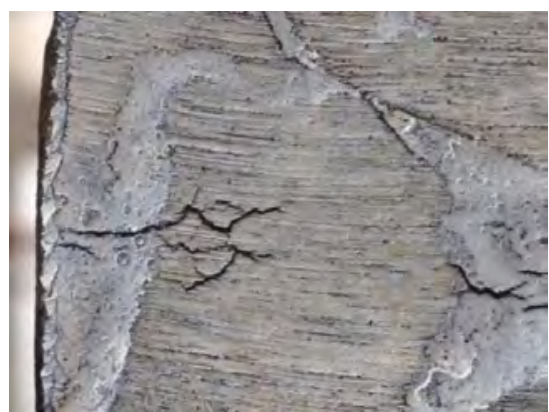

b) 5 million cycles

Fig.8 Surface Cracks in Butt Weld at Diagonal Web Flange

Structural hot spot stress at weld toe generally refers to stress perpendicular to weld line or the first main stress. The test discussed in this paper adopts the stress perpendicular to the weld line[3, 4]. Stress measuring points are arranged at places some distance away from the weld line to measure the strain near the weld so as to extrapolate the hot spot stress at the weld toe. The extrapolation empirical formulas are differently written as per the different number of measuring points as well as the different distance from the weld line. In light of the suggestion by the International Welding Specialist (IWS)[5], this paper arranges strain gauges from the weld $0.4 \mathrm{t}$ and $1.0 \mathrm{t}$. Hence, the formula:

$$
\varepsilon_{h s}=1.67 \cdot \varepsilon_{0.4 t}-0.67 \cdot \varepsilon_{1.0 t}
$$

Suppose the nominal strain measured in a location far away from the weld is $\varepsilon_{n}$, then the measured structural stress concentration factor at the weld toe can be obtained by the following formula:

$$
K_{s}=\frac{\sigma_{s}}{\sigma_{n}}=\frac{E \varepsilon_{h s}}{E \varepsilon_{n}}=\frac{\varepsilon_{h s}}{\varepsilon_{n}}
$$

where ${ }^{\sigma_{s}}$ refers to the maximum value of structural stress and ${ }^{\sigma_{n}}$ refers to the nominal stress.

Constructed in the finite element model of joints are the models for shell element and solid element, respectively, as shown in Figure 9. According to the results of the finite element analysis, the stress distribution, in terms of size and displacement, is well agreed with the measured values.

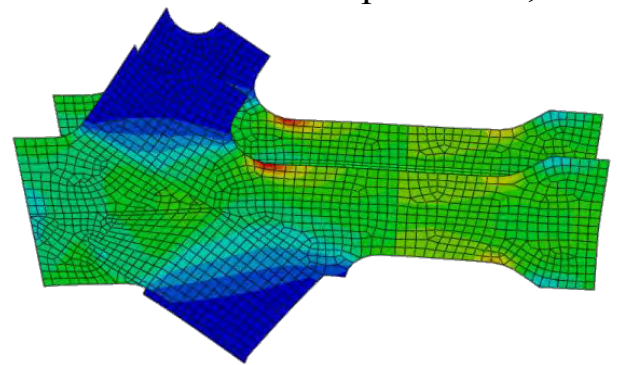

a) Shell element model

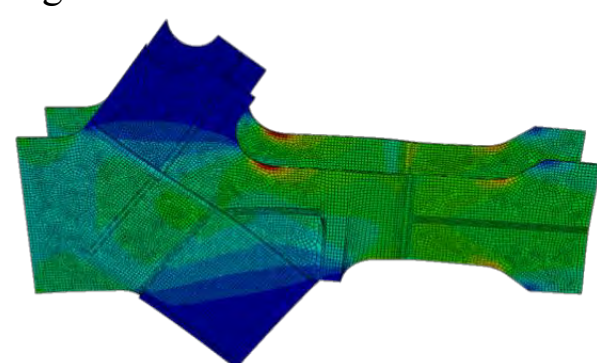

b) Solid element model

Fig. 9 Stress Distribution from the FE Model of Joints

Provided in the Table 2 is the measured values of stress concentration factor at various weld toes of KT-joints. The stress concentration caused by weld geometry not being considered, the measured joint SCF values obtainable from the Table 2 fall within the range of 1.2 1.25, to a low degree of stress concentration. 
Tab. 2 Measured Values of Stress Concentration Factor for Full-scaled Joint Specimens

\begin{tabular}{|c|c|c|c|}
\hline \multirow{3}{*}{$\begin{array}{l}\text { No. of Cycles } \\
\mathrm{Ni}\end{array}$} & \multicolumn{3}{|c|}{ Measured values of SCF joints } \\
\hline & \multicolumn{2}{|c|}{$\begin{array}{l}\text { Butt welds in flange of diagonal } \\
\text { chords }\end{array}$} & $\begin{array}{l}\text { Y-joint between diagonal chords } \\
\text { and bottom slab of box chords }\end{array}$ \\
\hline & $\begin{array}{l}\text { The side of } \\
\mathrm{t}=24 \mathrm{~mm}\end{array}$ & $\begin{array}{l}\text { The side of } \\
\mathrm{t}=30 \mathrm{~mm}\end{array}$ & $\begin{array}{l}\text { At web side of diagonal } \\
\text { chords }\end{array}$ \\
\hline 5 million & 1.23 & 1.19 & 1.2 \\
\hline 2 million & 1.25 & 1.24 & 1.19 \\
\hline 3.5 million & 1.25 & 1.21 & 1.21 \\
\hline 5 million & 1.21 & 1.18 & 1.22 \\
\hline
\end{tabular}

\section{Fatigue Tests of Butt Welds in the Roof Plate and Web Palte of Upper Chords, and Butt Welds on Flange of Diagonal Chords}

In the test of the first group of specimens (XSP1-1、XSP1-2、XSP2-1、XSP2-2), plate-through cracks are found via test of magnetic particle, after 3 million cycles of load, at the interface between the T-web butt weld and the scallop hole in the specimen XSP1-1, as shown in Figure 10. The cracks initiate in welds toe, corresponding to the structure stress amplitude of $70 \mathrm{MPa}$. Then the specimen XSP1-1 is replaced with the specimen FSP3-1 from the second group of specimens and the test continues till 6 million cycles of load are finished. It is demonstrated that the rest three specimens do not display any development of fatigue cracks.

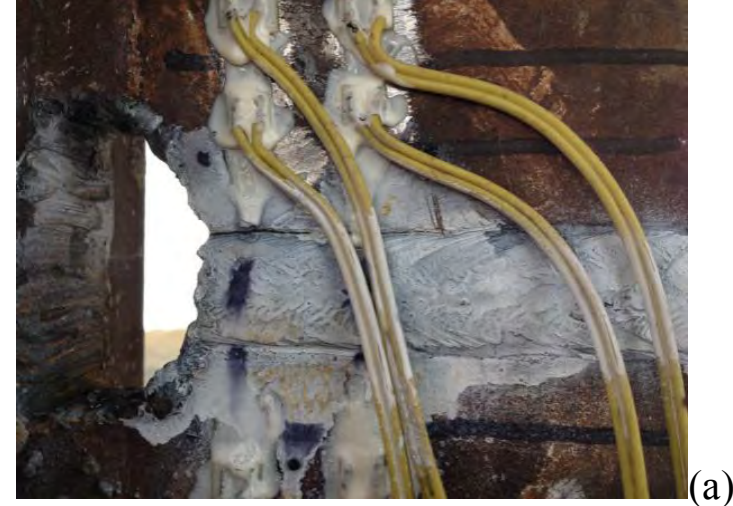

a)Magnetic particle test finds cracked welds (cracks in weld toe)

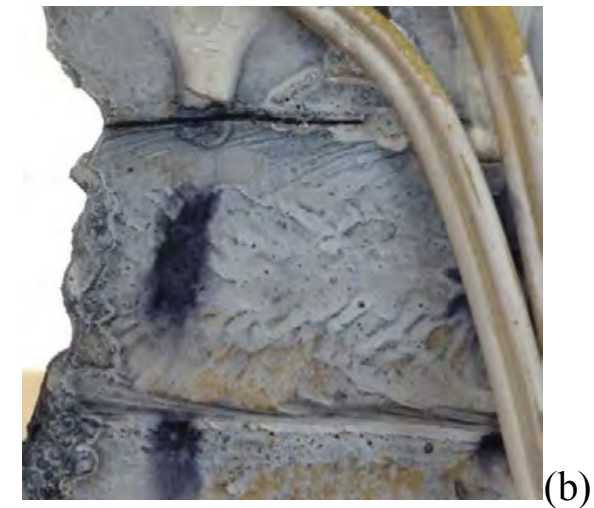

b) Enlarged picture of the cracks

Fig. 10 Location of Cracks via Magnetic Particle Test

Tab. 3 Measured Values of Group A Stress Concentration Factor for T Specimen Welds

\begin{tabular}{|c|c|c|c|c|c|}
\hline \multirow[b]{4}{*}{$\begin{array}{l}\text { No. Of } \\
\text { Cycles Ni }\end{array}$} & \multicolumn{5}{|c|}{ Measured value of SCF welded joints } \\
\hline & \multicolumn{3}{|c|}{ Specimen XSP1 } & \multicolumn{2}{|c|}{ Specimen XSP2 } \\
\hline & \multicolumn{2}{|l|}{ Web } & \multirow[b]{2}{*}{\begin{tabular}{l}
\multicolumn{1}{c}{ Flange } \\
Inner side \\
near \\
scallop \\
hole
\end{tabular}} & Web & Flange \\
\hline & $\begin{array}{l}\text { Transverse } \\
\text { butt welded } \\
\text { toes ( } 5 \mathrm{~mm} \\
\text { from scallop } \\
\text { hole) }\end{array}$ & $\begin{array}{l}\text { Transverse } \\
\text { butt } \\
\text { welded } \\
\text { toes (20 } \\
\text { mm from } \\
\text { scallop } \\
\text { hole) }\end{array}$ & & $\begin{array}{l}\text { Top of } \\
\text { scallop } \\
\text { hole }\end{array}$ & $\begin{array}{l}\text { Transverse butt } \\
\text { welds }\end{array}$ \\
\hline 5 million & 1.48 & 1.19 & 1.48 & 1.71 & 1.53 \\
\hline 3 million & 1.45 & 1.2 & 1.42 & 1.63 & 1.57 \\
\hline 6 million & 1.51 & 1.21 & 1.41 & 1.69 & 1.54 \\
\hline FEM & 1.46 & 1.33 & 1.21 & 1.64 & 1.52 \\
\hline
\end{tabular}


Tab.4 Measured Values of Group B Stress Concentration Factor for T Specimen Welds

\begin{tabular}{|l|c|l|}
\hline \multirow{2}{*}{ Ni No. Of Cycles Ni } & \multicolumn{2}{|c|}{ Measured value of SCF welded joints } \\
\cline { 2 - 3 } & Specimen FSP3 \\
\cline { 2 - 3 } & Web & \multirow{2}{*}{ Flange } \\
\cline { 2 - 3 } & Top of scallop hole & Transverse butt welds \\
\hline 5 million & 1.73 & 1.39 \\
\hline 3 million & 1.75 & 1.41 \\
\hline 6 million & 1.73 & 1.38 \\
\hline FEM & 1.63 & 1.40 \\
\hline
\end{tabular}

In the test of the second group of specimens (FSP3-1, FSP3-2, FSP3-3, FSP3-4), after application of 5 million cycles of load, with FSP3-1 experiencing 8 million cycles of load, no development of cracks is found in any of the four specimens.

Formula (1) and Formula (2) are used to do the calculation of stress concentration factor for T-specimen. The two groups of specimens are given in Table 3 and Table 4. In the tables, the range of SCF is found to fall within 1.2 1.75, with obvious increase of SCF near the scallop hole. The most severe stress concentration is found at the top of scallop hole, that is, at about 1.7.

\section{Conclusion}

The fatigue test of the full scaled KT-joint: In the fatigue test, the full-scaled Q14 joint specimen, subjected to 5 million cycles of load as much as the stress amplitude of the actual bridge's operating load, is found via magnetic particle test to have welds defect but no obvious development of fatigue crack, demonstrating that the actual bridge will not display fatigue failure within the designed time limit.

The fatigue test of T-joint: Fatigue failure is found only in specimen XSP1-1 of Group A and no fatigue crack is found in the rest specimens. As the specimen XSP1-1 has serious welding defect that causes stress concentration to significantly reduce fatigue resistance of the specimen. But the specimen XSP1-2, whose geometrical shape and load is completely the same as that of XSP1-1, does not display any cracks after 6 million cycles of load acted on it, displaying great fatigue strength discreteness. This explains that as weld defect significantly influences fatigue strength of welded joint, welding process and quality must be put under rigorous control.

\section{References}

[1]Radaj D, Sonsino CM, Fricke W. Recent developments in local concepts of fatigue assessment of welded joints[J]. Int J Fatigue. 2009;31(1):2-11.

[2]Radaj D, Sonsino CM, Fricke W. Fatigue assessment of welded joints by local approaches[M]: Woodhead publishing; 2006.

[3]Chattopadhyay MA, Glinka G, El-Zein M, Qian J, Formas MR. Stress analysis and fatigue of welded structures[J]. Welding in the World. 2011;55(7-8): 2-21.

[4]Miki C, Tateishi K. Fatigue strength of cope hole details in steel bridges[J]. Int J Fatigue. 1997;19(6):445-55.

[5]Fricke W. IIW guideline for the assessment of weld root fatigue[J]. Welding in the World. 2013:1-39. 